\title{
Immediate Effects of Chest Physiotherapy on Hemodynamic, Metabolic, and Oxidative Stress Parameters in Subjects With Septic Shock
}

\author{
Rafael S dos Santos MSc, Márcio VF Donadio PhD, Gabriela V da Silva MSc, \\ Clarissa N Blattner PhD, Denizar AS Melo PhD, Fernanda B Nunes PhD, \\ Fernando S Dias PhD, Eamim D Squizani, Leonardo Pedrazza MSc, \\ Isabella Gadegast, and Jarbas $\mathrm{R}$ de Oliveira $\mathrm{PhD}$
}

\begin{abstract}
BACKGROUND: Septic shock presents as a continuum of infectious events, generating tissue hypoxia and hypovolemia, and increased oxidative stress. Chest physiotherapy helps reduce secretion, improving dynamic and static compliance, as well as improving secretion clearance and preventing pulmonary complications. The purpose of this study was to evaluate the immediate effect of chest physiotherapy on hemodynamic, metabolic, inflammatory, and oxidative stress parameters in subjects in septic shock. METHODS: We conducted a quasi-experimental study in 30 subjects in septic shock, who underwent chest physiotherapy, without associated heart diseases and with vasopressors $<0.5 \mu \mathrm{g} / \mathrm{kg} / \mathrm{min}$. Venous and arterial blood gases, clinical and hemodynamic data, inflammatory data, lactate, and oxidative stress were evaluated before and $\mathbf{1 5}$ min after physiotherapy. RESULTS: Thirty subjects with a mean age of $61.8 \pm 15.9 \mathrm{y}$ and Sequential Organ Failure Assessment of 8 (range 6-10) were included. Chest physiotherapy caused a normalization of $\mathrm{pH}(P=.046)$ and $\mathrm{P}_{\mathrm{aCO}_{2}}(P=.008)$; reduction of lactate $(P=.001)$; and an increase in $\mathrm{P}_{\mathrm{aO}_{2}}$ $(P=.03)$, arterial oxygen saturation $(P=.02)$, and $\mathrm{P}_{\mathrm{aO}_{2}} / \mathrm{F}_{\mathrm{IO}_{2}}(P=.034), 15 \mathrm{~min}$ after it was applied. CONCLUSIONS: The results indicate that chest physiotherapy has immediate effects, improving oxygenation and reducing lactate and oxidative damage in subjects in septic shock. However, it does not cause alterations in the inflammatory and hemodynamic parameters. Key words: shock; septic; chest physiotherapy; oxidative stress; lactate; oxygen; intensive care. [Respir Care 2014;59(9):1398-1403.

(C) 2014 Daedalus Enterprises]
\end{abstract}

\section{Introduction}

Severe sepsis (an infection that leads to secondary acute organ dysfunction) and septic shock (severe sepsis with irreversible hypotension and resuscitation with fluids) are

Dr dos Santos is affiliated with the Faculdade de Fisioterapia; Drs Donadio, Blattner, and Melo are affiliated with the Faculdade de Enfermagem, Nutrição e Fisioterapia; Drs Silva, Ms Squizani, and Dr Pedrazza are affiliated with the Faculdade de Farmácia; Dr Nunes, Ms Gadegast, and Dr Oliveira are affiliated with the Faculdade de Biociências; and Dr Dias is affiliated with the Faculdade de Medicina, Pontificia Universidade Catolica do Rio Grande do Sul, Porto Alegre, Rio Grande do Sul, Brazil. Drs dos Santos and Blattner are affiliated with Hospital São Lucas, Porto Alegre, Rio Grande do Sul, Brazil.

The authors have disclosed no conflicts of interest.
2 of the greatest health problems affecting millions of individuals worldwide every year. ${ }^{1}$

Sepsis is an infectious event with hemodynamic consequences caused by the relationship between apoptotic, anti-inflammatory, and pro-inflammatory mediators. ${ }^{1}$ The primary stages of sepsis can be accompanied by circulatory failure resulting from hypovolemia, myocardial depression, increased metabolic rate, and perfusion abnor-

\footnotetext{
Corresponding author: Dr Denizar AS Melo, Pontifícia Universidade Católica do Rio Grande do Sul, PUCRS, Av Ipiranga, ${ }^{\circ}$ 6681, pd. 12/8 ${ }^{\circ}$, CEP: 90619-900, Porto Alegre, Rio Grande do Sul, Brazil. E-mail: dmelo@pucrs.br.
}

DOI: $10.4187 /$ respcare.02859 
malities (between the oxygen demand and reserve ratio) causing global tissue hypoxia. ${ }^{2,3}$

In septic shock, metabolic acidosis is characterized by a $\mathrm{pH}<7.35$ with a reduction of the bicarbonate content. It may also be associated with an elevation of serum lactate levels, giving these patients a worse prognosis because the serum lactate increase is associated with worse tissue oxygenation and a consequent uncoupling of the mitochondrial respiratory chain. However, there are other factors that can cause the elevation of serum lactate that are not necessarily connected to infection and mitochondrial dysfunction. ${ }^{2}$

Oxidative stress is one of the main contributing factors to increased mortality in several diseases, including septic shock. Oxidative stress caused by endotoxins can diminish the free radical catalysts or suppressors. Moreover, oxidative stress, induced by endotoxins, may regulate the production of tumor necrosis factor alpha, occurring as the result of bacterial or endotoxic translocation and reducing the function in several states of the disease. Nitric oxide has been involved in the pathogeny of vascular hyperresponsivity (hypotension in septic shock). However, nitric oxide may not be the only mediator of tissue injury and cytotoxicity caused by endotoxins. Therefore, it is important to evaluate the potential of free radicals in sepsis and septic shock patients with metabolic disorders. ${ }^{4}$ Indeed, the mitochondrion also plays an important role in cellular energy, and its structure and function are markedly affected by the physiopathology of sepsis. In particular, its high reactivity composes peroxynitrite, generated by the reaction of nitric oxide and superoxidase anions, mitochondrial inhibition enzymes and nucleic acids, and proteins and injured lipids. ${ }^{5}$

Physiotherapy has proved to be an important component in the management of patients in ICUs and has shown short-term and medium-term benefits. Chest physiotherapy results in physiological changes, such as significant alterations in hemodynamic, respiratory, and intracranial parameters. ${ }^{6,7}$ Indeed, it helps reduce retention or airway secretions, improving dynamic and static compliance, ${ }^{8}$ in addition to improving secretion clearance and preventing pulmonary complications, ${ }^{9}$ potentially reducing the stay in the ICU. Furthermore, a study by Pattanshetty and Gaude ${ }^{10}$ revealed that the mortality rate was observed to be lower in subjects in a specific chest physiotherapy regimen. More successful weaning was also observed. In another study, ${ }^{11}$ it was not possible to be clear about the reduction of mortality levels when chest physiotherapy was used in subjects in septic shock, although the study demonstrated that there were no deleterious effects from the use of the therapeutic modality.

Although many studies evaluate the hemodynamic, respiratory system mechanics, and airway clearance effects of chest physiotherapy, ${ }^{12,13}$ there are few data on the immediate effects of chest physiotherapy on inflammatory and oxidative stress parameters. Thus, the purpose of this

\section{QUICK LOOK}

\section{Current knowledge}

Chest physiotherapy results in physiological changes, including significant alterations in the hemodynamic, respiratory, and intracranial variables. Septic shock is a common reason for ICU admission and mechanical ventilation characterized in part by metabolic and oxidative stress. The impact of chest physiotherapy against the backdrop of septic shock has not been described.

\section{What this paper contributes to our knowledge}

Following chest physiotherapy, there were minor changes in blood gases that failed to reach clinical importance. There were also no alterations in inflammatory, oxidative damage, and hemodynamic parameters.

study was to evaluate the immediate effect of chest physiotherapy on inflammatory, metabolic, oxidative stress, and hemodynamic parameters in subjects with septic shock hospitalized in an adult ICU.

\section{Methods}

This study is a quasi-experimental study (of the before and after type) in which the hemodynamic, metabolic, inflammatory, and oxidative stress variables of subjects in septic shock who received conventional chest physiotherapy were evaluated.

The study included 30 subjects in the adult ICU at Hospital São Lucas of the Pontifical Catholic University of Rio Grande do Sul. The subjects (30-80 y old) were under invasive mechanical ventilation and sedated, with a diagnosis of septic shock (diagnostic criteria of Rivers et $\mathrm{al}^{3}$ ) and a prescription for chest physiotherapy. The intervention performed consisted of the first chest physiotherapy after it had been prescribed. Patients whose chest physiotherapy had been momentarily suspended using vasopressors $>0.5 \mu \mathrm{g} / \mathrm{kg} / \mathrm{min}$ and subjects with associated heart diseases were excluded.

\section{Physiotherapeutic Intervention}

The subjects included in this study received chest physiotherapy, which lasted $\sim 15 \mathrm{~min}$ and consisted of expiratory rib cage compression, vibrations, and manual hyperinflation associated with tracheal aspiration. The subjects included in this study received their first chest physiotherapy after the diagnosis of septic shock. All subjects were positioned in dorsal decubitus to perform the chest maneuvers. Expiratory rib cage compression consists of pro- 
ducing mechanical force transferred through the chest wall into the airways during the expiratory phase for the purpose of increasing and redirecting air flow, for pulmonary re-expansion and airway clearance. ${ }^{14}$ The vibrations were performed by isometric contraction of the forearm muscles, working in synergy with the palms of the hands perpendicular to the chest, to improve mucociliary depuration. ${ }^{14}$ Manual hyperinflation was performed using a manual hyperinflation device (Ambu, Glen Burnie, Maryland) with inspiratory pressure $<40 \mathrm{~cm} \mathrm{H}_{2} \mathrm{O}$ and $\mathrm{F}_{\mathrm{IO}_{2}}$ at 0.6 , inducing a tidal volume increase and generating subsequent improvement in pulmonary compliance, inspiratory flow, and bronchial secretion clearance. ${ }^{15}$ Manual hyperinflation was performed at the same time as the tracheal aspiration process, with 5-6 ventilatory cycles at each tracheal aspiration. Tracheal aspiration was performed using a size 10 or 12 aspiration cannula (CPL Medicals, São Paulo, Brazil) and saline solution at $0.9 \%$ (using at most $10 \mathrm{~mL}$ throughout the aspiration process), which was introduced slowly and gently to remove secretions. ${ }^{14}$ The number of aspirations performed depended on the subject's amount of secretions. The vacuum level was standardized at $30 \mathrm{~cm} \mathrm{Hg}$.

During implementation of the techniques, $\mathrm{S}_{\mathrm{pO}_{2}}$, heart rate, breathing frequency, and mean arterial pressure were monitored to control the effects while the protocol was performed (data not shown).

\section{Ventilator Data}

The subjects were ventilated at controlled pressure, with PEEP between 6 and $8 \mathrm{~cm} \mathrm{H}_{2} \mathrm{O}$ and $\mathrm{F}_{\mathrm{IO}_{2}}$ between 0.5 and 0.6 . The inspiratory pressure values were measured to ensure the ideal tidal volume for the subject, established as $5-6 \mathrm{~mL} / \mathrm{kg}$.

\section{Data Collection}

Evaluations and collections of samples were performed at 2 points in time. The first collection occurred 5 min before the physiotherapy session (control measure) and included hemodynamic and clinical data: mean arterial pressure, systolic arterial pressure, diastolic arterial pressure, peripheral oxygen saturation, heart rate, and breathing frequency. Blood was also collected for arterial blood gas (arterial $\mathrm{pH}, \mathrm{P}_{\mathrm{aO}_{2}}, \mathrm{P}_{\mathrm{aCO}_{2}}$, bicarbonate, and arterial oxygen saturation) and venous blood gas (venous $\mathrm{pH}$, venous oxygen partial pressure, venous carbon dioxide partial pressure, bicarbonate, and venous oxygen saturation). The plasma was separated to analyze lactate, thiobarbituric acid-reactive substance (TBARS), nitric oxide, and transforming growth factor beta. The second collection occurred $15 \mathrm{~min}$ after ending the physiotherapeutic intervention, and the same data were collected as during the first collection.

\section{Clinical and Hemodynamic Evaluations}

Clinical and hemodynamic analyses were evaluated according to the routine of the unit using a multiparametric monitor (Dash 4000, GE Healthcare, Madison, Wisconsin) that supplies the data for heart rate, peripheral oxygen saturation, mean arterial pressure, systolic arterial pressure, and diastolic arterial pressure. Breathing frequency was evaluated using the data estimated with the invasive mechanical ventilator (Servo-i, Maquet, Wayne, New Jersey).

\section{Blood Gas and Biochemical Evaluations}

Blood gas (arterial and venous) was evaluated using an IL GEM Premier analyzer (Diamond Diagnostics, Hollister, MA). Plasma lactate was measured using a commercial kit for dry chemistry (Vitros, Ortho-Clinical Diagnostics, Johnson \& Johnson, Gateway, New Jersey).

\section{Plasma Transforming Growth Factor Beta Measurement}

The transforming growth factor beta plasma dosage was measured using the enzyme-linked immunosorbent assay technique with a kit from R\&D Systems (Minneapolis, Minnesota). The results were expressed in $\mathrm{ng} / \mathrm{mL}$.

\section{Evaluations of Oxidative Stress Parameters}

TBARSs were evaluated via the reaction of cellular peroxidation products with thiobarbituric acid, where $80 \%$ of these substances are malondialdehyde. Nitric oxide was evaluated using the Griess reaction.

\section{Sample Size}

The sample size was calculated using PEPI 4.0 (Programs for Epidemiologists) based on the study by Unoki et al ${ }^{16}$ using $\mathrm{P}_{\mathrm{aCO}_{2}}$ as the outcome variable. For a 5\% level of significance, a power of $90 \%$, and a minimal difference of $3.5 \mathrm{~mm} \mathrm{Hg}$ before and after intervention, a minimal total of 30 subjects were obtained.

\section{Statistical Analysis}

The quantitative variables were described using mean $\pm \mathrm{SD}$ (symmetrical distribution) or median and interquartile range (asymmetrical distribution). The Kolmogorov-Smirnov test was used for homogeneity. The qualitative variables were described by absolute and relative frequencies. The paired Student $t$ test was used to compare the samples before and after intervention in the normal samples. In samples of nonnormal distribution, the Wilcoxon test was used to compare the same moments. The results were considered significant 


\section{Chest Physiotherapy and Stress Parameters in Septic Shock}

Table 1. Characteristics and Clinical Data of Subjects

\begin{tabular}{lc}
\hline \hline \multicolumn{1}{c}{ Variables } & Values \\
\hline Subjects, $n$ & 30 \\
Males, $n(\%)$ & $20(66.7)$ \\
Age, mean $\pm \mathrm{SD}, \mathrm{y}$ & $61.8 \pm 15.9$ \\
Weight, mean $\pm \mathrm{SD}, \mathrm{kg}$ & $78.3 \pm 18.1$ \\
RASS, median (IQR) & $-2(0$ to -4$)$ \\
ICU stay, mean $\pm \mathrm{SD}, \mathrm{d}$ & $17.5 \pm 14.4$ \\
Septic shock, $n(\%)$ & \\
$\quad$ Pulmonary origin & $19(63.3)$ \\
$\quad$ Abdominal origin & $11(36.7)$ \\
Cause of admission, $n(\%)$ & $8(26.7)$ \\
$\quad$ Abdominal surgery & $20(66.7)$ \\
Pneumonia & $2(6.7)$ \\
$\quad$ Renal failure & $16(53.3)$ \\
Death, $n(\%)$ & $26(12-27)$ \\
APACHE II, median (IQR) & $8(6-10)$ \\
SOFA, median (IQR) & \\
& \\
\hline RASS = Richmond Agitation Sedation Scale & \\
IQR = interquartile range & \\
APACHE II $=$ Acute Physiology and Chronic Health Evaluation II & \\
SOFA = Sequential Organ Failure Assessment & \\
\hline
\end{tabular}

when $P<.05$. Prism 5.0 (GraphPad Software, San Diego, California) was used for data analysis.

\section{Ethical Aspects}

The families of the participants in the study were informed of the study goal and invited to participate. After the study to be performed was appropriately explained to the individuals responsible for the participants, they received and signed the free informed consent. The study was approved by the university ethics and research committee (approval 11/05550)

\section{Results}

A total of 30 subjects were included in the study. Table 1 shows the characteristics and clinical data of the subjects. They were mostly male $(67.7 \%)$, and the mean age was $61.8 \pm 15.9$ y. Subjects in septic shock with a pulmonary infection origin predominated, and the Sequential Organ Failure Assessment scoring system index of these subjects was 8 (range 6-10). Sixteen subjects (53.3\%) died.

As for the arterial blood gases (Table 2), there was a significant increase in arterial $\mathrm{pH}, \mathrm{P}_{\mathrm{aO}_{2}}$, and arterial oxygen saturation $15 \mathrm{~min}$ after physiotherapeutic intervention. There was also a significant reduction in $\mathrm{P}_{\mathrm{aCO}}, 15 \mathrm{~min}$ after physiotherapy. When evaluating the $\mathrm{P}_{\mathrm{aO}_{2}} / \mathrm{F}_{\mathrm{IO}}$, a significant increase was obtained (Fig. 1).

In the venous blood gas data, there was no significant difference in venous carbon dioxide partial pressure, ve-
Table 2. Arterial and Venous Blood Gas Data Before and After Chest Physiotherapy

\begin{tabular}{|c|c|c|c|}
\hline & Before & 15 min After & $P$ \\
\hline \multicolumn{4}{|c|}{ Arterial blood gases } \\
\hline $\mathrm{pH}$ & $7.36 \pm 0.11$ & $7.38 \pm 0.12$ & $.046^{*}$ \\
\hline $\mathrm{P}_{\mathrm{aCO}_{2}}$ & $39 \pm 12$ & $36 \pm 11$ & $.008 *$ \\
\hline $\mathrm{P}_{\mathrm{aO}_{2}}$ & $104 \pm 41$ & $119 \pm 50$ & $.03 *$ \\
\hline Bicarbonate & $21 \pm 5$ & $22 \pm 6$ & .37 \\
\hline $\mathrm{S}_{\mathrm{aO}_{2}}$ & 98 (95-99) & 98 (96-99) & $.02 \dagger$ \\
\hline \multicolumn{4}{|c|}{ Venous blood gases } \\
\hline $\mathrm{pH}$ & $7.31 \pm 0.12$ & $7.34 \pm 0.11$ & $.003 *$ \\
\hline $\mathrm{P}_{\mathrm{vCO}_{2}}$ & $45 \pm 12$ & $43 \pm 11$ & .12 \\
\hline $\mathrm{P}_{\overline{\mathrm{v}} \mathrm{O}_{2}}$ & $45 \pm 8$ & $45 \pm 10$ & .80 \\
\hline Bicarbonate & $22 \pm 7$ & $23 \pm 7$ & .68 \\
\hline $\mathrm{S}_{\overline{\mathrm{v}}_{2}}$ & $74 \pm 9$ & $75 \pm 7$ & .85 \\
\hline \multicolumn{4}{|c|}{$\begin{array}{l}\text { Values are presented as mean } \pm \mathrm{SD} \text { (symmetric variables) and median and interquartile range } \\
\text { (asymmetric variables). } \\
\text { * Significant differences by the paired Student } t \text { test } \\
\dagger \text { Significant differences by the Wilcoxon test } \\
\mathrm{S}_{\mathrm{aO}_{2}}=\text { arterial oxygen saturation } \\
\mathrm{P}_{\mathrm{vCO}_{2}}=\text { venous carbon dioxide partial pressure } \\
\mathrm{P}_{\mathrm{vO}_{2}}=\text { mixed venous partial pressure of oxygen } \\
\mathrm{S}_{\mathrm{vO}_{2}}=\text { venous oxygen saturation }\end{array}$} \\
\hline
\end{tabular}

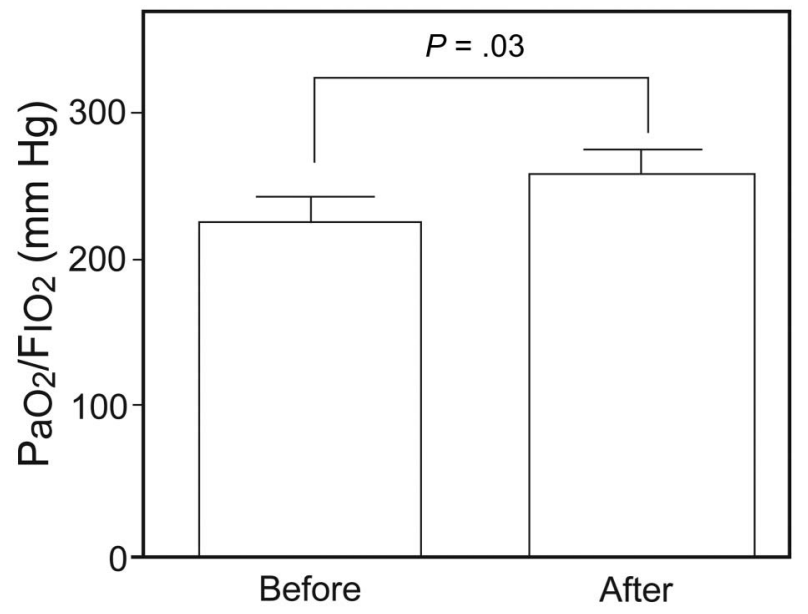

Fig. 1. $\mathrm{P}_{\mathrm{aO}_{2}} / \mathrm{F}_{1 \mathrm{O}_{2}}$ before and $15 \mathrm{~min}$ after chest physiotherapy.

nous oxygen partial pressure, and venous oxygen saturation $15 \mathrm{~min}$ after these subjects had physiotherapy. However, a significant increase in venous $\mathrm{pH}$ was seen $15 \mathrm{~min}$ after the intervention (see Table 2).

The clinical and hemodynamic results collected at bedside before and $15 \mathrm{~min}$ after the physiotherapeutic intervention are shown in Table 3. A significant increase in $\mathrm{S}_{\mathrm{pO}_{2}}$ was observed, but there were no significant alterations in heart rate, breathing frequency, and arterial pressure values.

As for the effect of physiotherapy on lactate, a significant reduction was shown 15 min after physiotherapy (Fig. 2). In the oxidative stress data evaluation, chest physio- 


\section{Chest Physiotherapy and Stress Parameters in Septic Shock}

Table 3. Clinical and Hemodynamic Data Before and After Chest Physiotherapy

\begin{tabular}{lccc}
\hline \hline & Before & $\begin{array}{c}15 \text { min } \\
\text { After }\end{array}$ & $P$ \\
\hline $\mathrm{S}_{\mathrm{pO}_{2}}$ & $98 \pm 3$ & $99 \pm 2$ & $.02 *$ \\
Heart rate (beats/min) & $94 \pm 19$ & $97 \pm 17$ & .07 \\
Breathing frequency (breaths/min) & $20 \pm 4$ & $20 \pm 4$ & .06 \\
Systolic arterial pressure & $129 \pm 25$ & $132 \pm 23$ & .50 \\
Diastolic arterial pressure & $66 \pm 13$ & $67 \pm 12$ & .88 \\
Mean arterial pressure & $87 \pm 17$ & $88 \pm 16$ & .88
\end{tabular}

Values are presented as mean \pm SD (symmetric variables).

* Significant difference by the paired Student $t$ test.

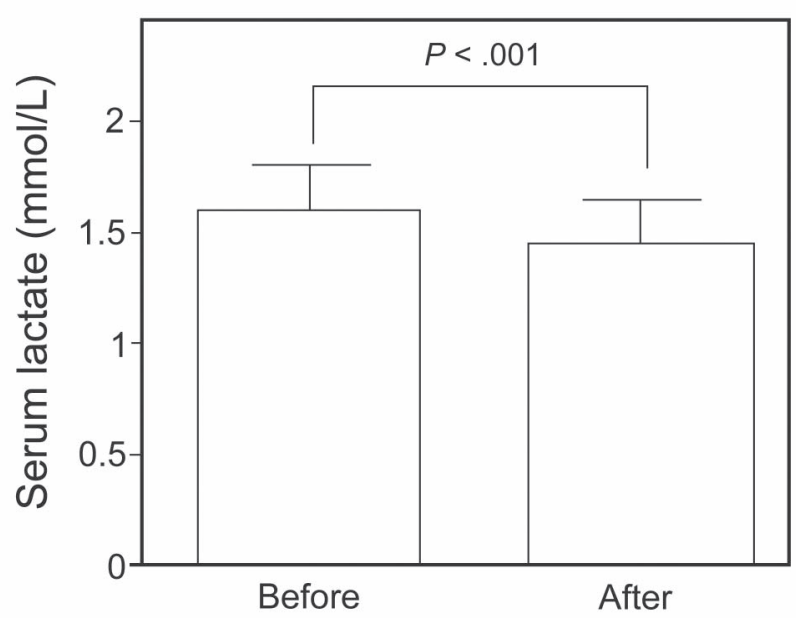

Fig. 2. Serum lactate values before and $15 \mathrm{~min}$ after chest physiotherapy.

therapy did not provoke a reduction in the TBARS plasma concentration, and there was no significant difference in nitric oxide and transforming growth factor beta.

\section{Discussion}

This study was conducted to evaluate whether physiotherapy can have immediate beneficial effects (15 $\mathrm{min})$ on parameters that can influence the survival of a subject in septic shock. The results indicate that chest physiotherapy is conducive to better tissue oxygenation with important metabolic effects.

Fifteen min after the intervention, it was possible to detect important beneficial effects in these subjects. We obtained an elevation of the $\mathrm{P}_{\mathrm{aO}}$, and this can be considered an important result, considering that improved oxygenation in subjects with septic shock makes it possible to have greater tissue oxygenation, reducing ischemia that results from vascular complications and a possible delay in the organic dysfunction process. ${ }^{1,3}$ In addition, we dem- onstrated a reduction in the serum lactate, indicating an increase in tissue oxygenation as a consequence of better blood perfusion. On the other hand, the serum lactate reduction, associated with normalization of the $\mathrm{P}_{\mathrm{aCO}_{2}}$ and arterial and venous $\mathrm{pH}$, modulates the cellular environment, which also helps decrease free radical production.

The elevation of $\mathrm{P}_{\mathrm{aO}_{2}}$ levels appears to be directly related to improvement in the gas exchange capacity and consequent hyperoxygenation, which may be provided by the physiotherapeutic intervention. In a previous study ${ }^{17}$ on subjects during the immediate postoperative period after heart surgery, this same elevation could be seen using the manual hyperinflation technique with PEEP. Furthermore, some studies show that manual hyperinflation can improve arterial oxygenation before and after tracheal aspiration, as well as $\mathrm{S}_{\mathrm{pO}_{2}}{ }^{18-20}$ which was also demonstrated in our study.

The $\mathrm{P}_{\mathrm{aO}_{2}} / \mathrm{F}_{\mathrm{IO}_{2}}$ significantly increased 15 min after intervention in our study. This is in contrast to the result shown by 2 previous studies, ${ }^{18,20}$ which did not find any effects on this parameter. This increase in the $\mathrm{P}_{\mathrm{aO}_{2}} / \mathrm{F}_{\mathrm{IO}_{2}}$ was due to the increase in $\mathrm{P}_{\mathrm{aO}}$ because the $\mathrm{F}_{\mathrm{IO}_{2}}$ values of the ventilator were not modified during the period of the study.

The significant reduction in $\mathrm{P}_{\mathrm{aCO}_{2}}$ shown in our study may be related to the improved alveolar ventilation, with possible recruitment of new pathways and consequent improvement of gas exchange. These results agree with a study by Barker and Adams, ${ }^{21}$ in which chest physiotherapy with manual hyperinflation and tracheal aspiration was performed. In addition, there is a relationship between the reduction of $\mathrm{P}_{\mathrm{aCO}_{2}}$ and the subsequent increase in venous $\mathrm{pH}$. Although no study evaluating the proposed procedure has demonstrated this effect, we believe that the increase in venous $\mathrm{pH}$ occurs due to a better distribution of oxygen and reduction of carbon dioxide, resulting in a less acidotic venous $\mathrm{pH}$.

The venous blood gas data in the present study were in accordance with the literature, in which no alterations were observed in the different techniques studied..$^{20,21}$ Regarding the clinical parameters (see Table 3), only a significant $\mathrm{S}_{\mathrm{pO}_{2}}$ increase was observed, although this alteration (98\% vs $99 \%$ ) is not relevant from the clinical perspective.

We also demonstrated an increased $\mathrm{P}_{\mathrm{aO}_{2}}$, which we believe could improve tissue perfusion. For this reason, we measured the plasma lactate concentration. We found that physiotherapy immediately reduced this concentration, showing that the procedure had a significant therapeutic effect. We can associate this reduction with an increase in $\mathrm{P}_{\mathrm{aO}_{2}}$, which may have provoked a longer use of the aerobic route, resulting in lower lactate production. ${ }^{22}$ In clinical practice, a lactate reduction of at least $10 \%$ may be a good indication of resuscitation.

In septic shock when tissue perfusion is reduced, it causes an increase in anaerobic metabolism and may cause direct tissue injury because of the depletion of adenosine triphosphate, which is needed to maintain the structural integrity of 


\section{Chest Physiotherapy and Stress Parameters in Septic Shock}

the cells. Cellular lesions may be intensified by free radicals when the offer of $\mathrm{O}_{2}$ follows a period of dysoxia. In our study, we evaluated the plasma concentration of TBARS, which result from the deleterious action of free radicals on cells. Our results did not show a significant drop in plasma TBARS. We also decided to evaluate the formation of nitric oxide, which, besides being a free radical, is a major inflammatory parameter. We did not see significant differences for this parameter 15 min after physiotherapy. We believe that this result is due to the time period used in our study because nitric oxide needs a metabolic route for synthesis (ie, more time may be needed to evaluate this effect).

Among the cytokines induced by septic shock, interleukin-1 and tumor necrosis factor alpha are the keys to the disease severity. However, therapies that neutralize these cytokines have not improved patient survival. During the course of the disease, lipopolysaccharide, a product of Gram-negative bacteria, provokes apoptosis of lymphocytes, thus diminishing defenses against infection and worsening the clinical picture of the patient. The reduction in apoptosis of immunocompetent cells may raise the organism's defenses, with consequent increases in anti-inflammatory cytokines, mainly interleukin-10 and transforming growth factor beta, which also have a strong immunosuppressive property. On the basis of these premises, we decided to evaluate the plasma concentration of transforming growth factor beta because we did not obtain a significant reduction of nitric oxide, an important metabolic inflammatory agent. However, no differences were seen in our results 15 min after treatment, again showing that the treatment did not alter the inflammatory condition of the subject in the short term $(15 \mathrm{~min})$.

Some limitations were identified in this study. The quantity and type of vasopressors and sedatives used by the subjects in this study were varied, and we could not control these data. The sepsis time could not be calculated because the subjects were diagnosed only when they were admitted to our ICU, and not when they were admitted to hospital.

\section{Conclusions}

The results indicate that chest physiotherapy induces immediate effects, improving oxygenation and diminishing lactate in subjects with septic shock, but it does not induce alterations in inflammatory, oxidative damage, and hemodynamic parameters.

\section{REFERENCES}

1. Maddirala S, Khan A. Optimizing hemodynamic support in septic shock using central and mixed venous oxygen saturation. Crit Care Clin 2010;26(2):323-333.

2. Otero RM, Nguyen HB, Huang DT, Gaieski DF, Goyal M, Gunnerson KJ, et al. Early goal-directed therapy in severe sepsis and septic shock revisited: concepts, controversies, and contemporary findings. Chest 2006;130(5):1579-1595.

3. Rivers E, Nguyen B, Havstad S, Ressler J, Muzzin A, Knoblich B, et al. Early goal-directed therapy in the treatment of severe sepsis and septic shock. N Engl J Med 2001;345(19):1368-1377.

4. Sakaguchi S, Furusawa S. Oxidative stress and septic shock: metabolic aspects of oxygen derived free radicals generated in the liver during endotoxemia. FEMS Immunol Med Microbiol 2006;47(2):167-177.

5. Hubbard WJ, Bland KI, Chaudry IH. The role of the mitochondrion in trauma and shock. Shock 2004;22(5):395-402

6. Wong WP, Paratz JD, Wilson K, Burns YR. Hemodynamic and ventilatory effects of manual respiratory physiotherapy techniques of chest clapping, vibration, and shaking in an animal model. J Appl Physiol 2003;95(3):991-998.

7. Zeppos L, Patman S, Berney S, Adsett JA, Bridson JM, Paratz JD. Physiotherapy intervention in intensive care is safe: an observational study. Aust J Physiother 2007;53(4):279-283.

8. Berti JS, Tonon E, Ronchi CF, Berti HW, Stefano LM, Gut AL, et al. Manual hyperinflation combined with expiratory rib cage compression for reduction of length of ICU stay in critically ill patients on mechanical ventilation. J Bras Pneumol 2012;38(4):477-486.

9. Ntoumenopoulos G, Presneill JJ, McElholum M, Cade JF. Chest physiotherapy for the prevention of ventilator-associated pneumonia. Intensive Care Med 2002;28(7):850-856.

10. Pattanshetty RB, Gaude GS. Effect of multimodality chest physiotherapy in prevention of ventilator-associated pneumonia: a randomized clinical trial. Indian J Crit Care Med 2010;14(2):70-76.

11. Sossdorf M, Otto GP, Menge K, Ralf A, Claus RA, Lösche W, Kabisch B, et al. Potential effect of physiotherapeutic treatment on mortality rate in patients with severe sepsis and septic shock: a retrospective cohort analysis. J Crit Care 2013;28(6):954-958.

12. Martí JD, Li Bassi G, Rigol M, Saucedo L, Ranzani OT, Esperatti M, et al. Effects of manual rib cage compressions on expiratory flow and mucus clearance during mechanical ventilation. Crit Care Med 2013; 41(3):850-856.

13. Siner JM. An exogenous cough. Crit Care Med 2013;41(3):929-930.

14. Sarmento GL. Fisioterapia respiratória no paciente clínico: rotinas clínicas, 2nd edition. São Paulo: Manole; 2007:7-22.

15. Paratz J, Lipman J, McAuliffe M. Effect of manual hyperinflation on hemodynamics, gas exchange, and respiratory mechanics in ventilated patients. J Intensive Care Med 2002;17(6):317-323.

16. Unoki T, Kawasaki Y, Mizutani T, Fujino Y, Yanagisawa Y, Ishimatsu $\mathrm{S}$, Tamura F, Toyooka H. Effects of expiratory rib-cage compression on oxygenation, ventilation, and airway-secretion removal in patients receiving mechanical ventilation. Respir Care 2005;50(11):1430-1437.

17. Blattner C, Guaragna JC, Saadi E. Oxygenation and static compliance is improved immediately after early manual hyperinflation following myocardial revascularisation: a randomised controlled trial. Aust J Physiother 2008;54(3):173-178.

18. Berney S, Denehy L. A comparison of the effects of manual and ventilation hyperinflation on static lung compliance and sputum production in intubated and ventilated intensive care patients. Physiother Res Int 2002;7(2):100-108.

19. Lemes DA, Guimarães FS. O uso da hiperinsuflação manual como recurso fisioterapêutico em unidade de terapia intensiva. Rev Bras Terapia Int 2007;19(2):222-225. Article in Portuguese.

20. Stiller K. Physiotherapy in intensive care: towards an evidence-based practice. Chest 2000;118(6):1801-1813.

21. Barker M, Adams S. An evaluation of a single chest physiotherapy treatment on mechanically ventilated patients with acute lung injury. Physiother Res Int 2002;7(3):157-169.

22. Dibartola S. Anormalidades de fluídos, eletrólitos e equilíbrio ácidobásico na clínica de pequenos animais, 1st edition. São Paulo: Roca; 2007;217-238. 